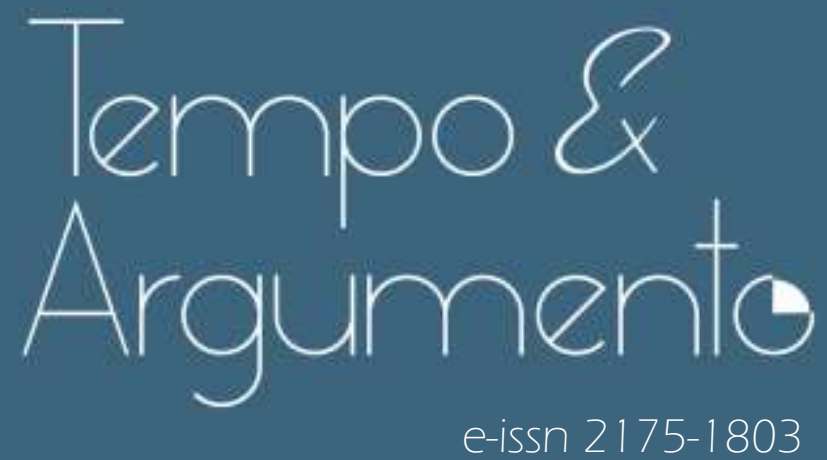

\title{
Compromisso e autonomia: uma guerra fria entre a Revolução Cubana e Ángel Rama
}

- Pedro Demenech

Doutor em História Social da Cultura pela Pontifícia Universidade Católica do Rio de Janeiro (PUC-Rio). Pesquisador de pós-doutorado, com bolsa FAPERJ Nota 10, no IESP-UERJ.

Rio de Janeiro, RJ - BRASIL

lattes.cnpq.br/3322954597724927

p_demenech@yahoo.com.br

(D) orcid.org/0000-0001-8247-1460

Para citar este artigo:

DEMENECH, Pedro. Compromisso e autonomia: uma guerra fria entre a Revolução Cubana e Ángel Rama. Tempo e Argumento, Florianópolis, v. 13, n. 33, e0206, maio/ago. 2021.

do: http://dx.doi.org/10.5965/2175180313332021e0206

Recebido: 07/05/2020

Aprovado: 17/03/2021 
Compromisso e autonomia: uma guerra fria entre a Revolução Cubana e Ángel Rama ${ }^{1}$

\begin{abstract}
Resumo
Este artigo trata da relação entre Ángel Rama (1926-1983) e o governo cubano no contexto da nova política cultural, adotada a partir de 1971. A influência da Guerra Fria e a relação entre intelectuais e Estado na América Latina norteiam o desenvolvimento deste tema, pois, em Cuba, diferente de outros países da América Latina, o Estado assumiu o monopólio das formas culturais ao endurecer e reorganizar as regras de criação cultural. Crítico desse modelo, Rama, que inicialmente apoiara a revolução, escreveu um longo artigo no qual procurou enumerar os erros e as possíveis saídas desse modelo, ao apontar que a liberdade de expressão e a crítica deveriam ter como compromisso propor mudanças e não reiterar programas políticos.
\end{abstract}

Palavras-chave: Ángel Rama; história intelectual; revolução Cubana; Guerra Fria.

\title{
Commitment and autonomy: a cold war between the Cuban Revolution and Ángel Rama
}

\begin{abstract}
This article deals with the relationship between Ángel Rama (1926-1983) and the Cuban government in the context of the new cultural policy, adopted since 1971. The influence of the Cold War and the relationship between intellectuals and the State in Latin America guide the development of this theme because, in Cuba, unlike other countries in Latin America, the State assumed a monopoly on cultural forms by hardening and reorganizing cultural creation rules. Critic of this model, Rama, who initially supported the revolution, wrote a long article in which he sought to list the errors and possible ways out of this model, pointing out that freedom of expression and criticism should be committed to proposing changes and not reiterating political programs.
\end{abstract}

Keywords: Ángel Rama; intellectual History; Cuban Revolution; Cold War.

\footnotetext{
Este artigo integra o projeto "Biblioteca Ayacucho: rede intelectual e transferência de saberes na formação de um cânon latino-americano", desenvolvido por mim, entre 2017 e 2020, na Pontifícia Universidade Católica do Rio de Janeiro (PUC-Rio) com a Bolsa de Pós-Doutorado Nota 10 da Fundação de Amparo à Pesquisa do Estado do Rio de Janeiro, processo no 202.380/2017.
} 


\section{Introdução}

Este artigo surgiu do desejo de trabalhar a atuação intelectual de Ángel Rama nos anos 1970, sobretudo o modo como ele teorizou a cultura e a literatura latinoamericanas. Foi nessa década que ele, além de romper, polemizou o governo de Cuba, em 1971, por causa da nova política cultural, no intuito de defender a autonomia crítica intelectual em relação ao Estado.

A questão que, inicialmente, motivou-me diz respeito ao interesse em compreender a relação entre intelectuais e Estado na América Latina, ainda bastante presente nos anos 1970. Essa relação, de acordo com Altamirano (2010), entre o final do século XIX e os anos 1980, durante aproximadamente um século, modificou-se quando o campo cultural adquiriu mais autonomia em relação ao Estado. Os intelectuais, que antes trabalhavam para a burocracia estatal a fim de garantir status e sustento, ganham outra função ao entrarem na esfera pública como escritores, jornalistas e professores universitários capazes de influenciar a criação, a circulação e a recepção de ideias sem necessariamente depender do poder público e seus dispositivos.

Esse processo, além de atravessar todo o século XX e de se atrelar a outros acontecimentos globais (como a Revolução Russa, as Duas Grandes Guerras, a Guerra Fria, as descolonizações na África e na Ásia e a desagregação da União Soviética), foi continental e transnacional. Guiado pelo conceito de revolução, ele atinge um pico entre 1959 e 1973, período no qual a Revolução Cubana e o golpe de Estado no Chile - em 11 de setembro, quando Augusto Pinochet (1915-2006) derrubou o governo de Salvador Allende (1908-1973) e tomou o palácio de La Moneda - dão um sentido ao lugar da América Latina no mundo.

Além do mais, neste trabalho, estabeleço um diálogo e uma aproximação com as propostas historiográficas de Rojas (2018) que, em La polis literaria, mostrou como a América Latina elaborou, no contexto da Guerra Fria, uma série de questões culturais que, embora conectadas, não são necessariamente políticas. Desde 1959, como mostrou Rojas, a Revolução Cubana teve um papel central na articulação dessas questões, pois, além de sua importância política, por mais de uma década, mobilizou todas as vertentes de esquerda na América Latina e produziu querelas ideológicas que remodelaram o sentido das reflexões a respeito das identidades 
nacionais e do latino-americanismo. É nesse cenário que as principais obras do boom literário latino-americano ganham destaque.

A palavra boom, desde aquele período, é polêmica e complexa para definir apenas um aspecto da literatura e da cultura na América Latina dos anos 1960 e 1970. Tratou-se mais de um fenômeno propiciado pela sociedade de consumo e impulsionado pelo mercado do que um movimento intelectual organizado, pois, de um lado, as traduções de escritores latino-americanos para outras línguas foram impulsionadas, sobretudo, pela curiosidade que a Revolução Cubana despertou sobre o continente e, do outro, essa recepção internacional teve um efeito positivo sobre os latino-americanos que, além do reconhecimento de suas obras, experimentaram uma intensa agitação social e cultural nesse período.

Como mostrou Rama (1985), inicialmente, o boom teve um respaldo crítico positivo, mas, à medida que foi sendo definido, acabou enquadrando a produção literária do continente segundo as normas de publicidade e mercado exigidas pela estrutura empresarial das grandes editoras. Devido a isso, a literatura moderna latino-americana que, pareceu estar concentrada apenas em alguns autores, era vista como cópia dos romances das vanguardas europeias ou produto dos meios de massa que desvinculava essas obras do lugar onde eram criadas. Todavia, contrariando essas normas, os próprios escritores do boom buscavam reverter a situação, honrando tanto suas referências como os outros escritores que, embora ignorados pelo grande público, possuíam ampla qualidade artística. Sendo assim, é importante distinguir o boom enquanto fenômeno literário e estético do boom enquanto fenômeno de mercado, que reduziu o primeiro, sobrepôs-se à produção literária e influenciou novas obras afetando o comportamento dos escritores como homens públicos.

Todavia, uma vez que o boom coincide com a Guerra Fria, é crucial lembrar que escritores - como Julio Cortázar, Augusto Roa Bastos, Gabriel García Márquez, Mario Vargas Llosa e Guillermo Cabrera Infante - e críticos - como Ángel Rama e Emir Rodríguez Monegal - nascidos entre os anos 1920 e 1930, começaram a publicar seus trabalhos e textos entre os anos 1940 e 1950, antes do triunfo revolucionário em Cuba. Mas, ao situarem-se dentro desse conflito ideológico, tanto a literatura como a crítica adquirem uma função política, pois a intelectualidade 
latino-americana viu-se obrigada a lutar contra as ditaduras e a questionar ou apoiar a luta que a esquerda travou pelo socialismo e pela democracia.

Como apontou Rojas (2018), é interessante retomar a forma como esses intelectuais trabalharam o conceito de revolução, pois a ideia de cada um sobre o que seria ou não revolucionário expõe as primeiras construções ideológicas das tensões sobre significado do socialismo, da democracia, da esquerda e do nacionalismo. Assim, à medida que ficam mais claros os significados do termo Revolução - escrito em maiúsculo, na maioria das vezes - entre os intelectuais daquele período, é possível distinguir melhor os discursos hegemônicos e oficiais daqueles que tinham mais autonomia intelectual. Dois conceitos são centrais naquilo que Rojas (2018) chamou de "políticas e poéticas do boom": revolução e ditadura. Desse modo, embora a ideia de que o autoritarismo tenha sido uma marca recorrente na história política da América Latina e do Caribe, é interessante verificar como esses conceitos são construídos de acordo com a tradição intelectual que os mobiliza. É fundamental, aliás, considerar que esses dois conceitos adquirem forma e sentido devido aos intelectuais que se dispunham a debatê-los.

Sendo assim, para retomar a questão que motivou este artigo, isto é, a relação entre intelectuais e Estado na América Latina, é importante mencionar que na época do boom os intelectuais já dispunham de meios, mais ou menos consolidados, que garantiam sua autonomia. O acesso ao mercado de livros, as editoras e os prêmios propiciaram esse caminho que também se consolidou, sobretudo, por causa das revistas especializadas e jornais que, por sua vez, tanto na América Latina como fora do continente, garantiram que esses escritores e críticos falassem e agissem publicamente contra o autoritarismo da direita e o dogmatismo da esquerda, além propiciar o refinamento do estilo e da argumentação das ideias a cada experiência de debate e de polêmica.

Revolução e Guerra Fria: intelectuais e guerrilha ou a construção de outra esquerda

Durante as décadas de 1960 e 1970, a sociedade, a política, a cultura e também a temporalidade na América Latina se moldaram pelo conceito de 
revolução² e suas antíteses - ora identificado com violência e o caos, ora assimilado pela capacidade de imaginar mundos ideais -, numa época em que as mudanças ou eram associadas à derrubada de um regime de governo inimigo e tirano ou eram vinculadas à manutenção da ordem e do regime democrático. Segundo González Alemán e Palieraki (2012), esses significados, embora coexistissem entre si, na maior parte das vezes produziam tensões que obrigavam o continente e seus agentes históricos, principalmente os intelectuais, a dirigirem energia e experiência para imaginar ações em função de um horizonte revolucionário.

Da mesma forma, esse horizonte revolucionário foi marcado pela Guerra Fria que, de acordo com Rouquié (2009), trouxe tardiamente para a América Latina as consequências da polarização entre Oriente socialista (despótico e autoritário) e Ocidente capitalista (“mundo livre”), sobretudo na década de 1960 quando a eclosão da Revolução Cubana levou os Estados Unidos (EUA) a redefinir sua política diplomática no continente. Tudo isso não apenas reascendeu a presença de movimentos de esquerda ligados à guerrilha, como deu aos militares um protagonismo político marcado, principalmente, pela tomada do poder através de golpes e pela construção de uma ideologia que pregava a existência de um inimigo interno que deveria ser combatido para frear a luta revolucionária, as mudanças sociais e o avanço do comunismo. Desse modo, em função de uma situação mais paranoica do que real, foi esboçada uma doutrina política de segurança nacional ${ }^{3}$ que justificava e legalizava a repressão praticada pelos regimes militares.

Como mostra Franco (2002), entre 1950 e 1980, a presença dessa ideologia bipolar na América Latina não apenas transformou o continente em um campo de batalha onde EUA e União Soviética (URSS) disputavam poder, como desrespeitou quaisquer especificidades locais. Segundo essa perspectiva, nem o capitalismo e nem o comunismo se adaptaram à realidade latino-americana, pois, em vez solucionar, acirraram os problemas continentais. De um lado, o comunismo não acabou com a pobreza, nem produziu soluções para as comunidades

\footnotetext{
O conceito de revolução, neste caso, relaciona-se com a descrição feita por Koselleck (2011). Variável do ponto de vista linguístico, seu significado não é unívoco e muda conforme o país e a situação política em que é usado. Por isso, para a história dos conceitos, em relação à política, é importante compreender a relação entre palavras e seus usos.

3 Sobre este assunto cf. a reflexão conceitual elaborada por Padrós (2004) a respeito de como a Doutrina de Segurança Nacional, na América Latina, assume a forma de terror de Estado.
} 
marginalizadas e as desigualdades. De outro, a intervenção ideológica e militar dos EUA, através do cinema, do recrutamento de intelectuais pela CIA e do uso das forças armadas, atacou constantemente as particularidades latino-americanas através de um suposto ideal universal baseado na ideia de Ocidente Cristão e democrático. ${ }^{4}$

Não à toa, segundo Iber (2015), a peculiaridade da Guerra Fria na América Latina foram as disputas marcadas pela presença de diferentes vocabulários políticos (liberalismo, socialismo, catolicismo e conservadorismo) mobilizados na esfera cultural. Alheios às tradições nacionais e regionais, esses vocabulários eram transformados pela literatura e pela crítica em elemento de polêmicas nas quais os intelectuais, alinhados - ou não - com as diretrizes estadunidenses ou soviéticas, procuravam traduzir e dar sentido a esse conflito externo que afetou diretamente as diferentes identidades internas do continente. Assim, nesse período, os Estados Unidos, através do Congresso pela Liberdade da Cultura, conduziram suas ações a partir de uma linguagem política centrada no conceito de "liberdade", enquanto a União Soviética, por meio do Conselho Mundial da Paz, se guiou pelo conceito de "paz". Todavia, após o triunfo da Revolução Cubana, essas instituições e suas respectivas linguagens se dividem entre o ideário humanista e a ideia de liberação nacional - que serviu para unificar as esquerdas - e o ideário cristão e as práticas autoritárias, usadas principalmente pelas direitas reacionárias.

Porém, como Pipetone (2015) aponta, as esquerdas, ainda que operassem com uma linguagem revolucionária, em vários aspectos do seu matiz ideológico, também tenderam para o autoritarismo, principalmente ao disseminar a guerrilha (urbana e rural) como elemento revolucionário. O triunfo da Revolução Cubana impôs consequências significativas para a América Latina, pois, de um lado, a adesão à ortodoxia soviética, o vanguardismo heroico e a ideologia marxistaleninista empobreceram a capacidade de refletir sobre as realidades regionais, e, do outro, as necessidades de figuras carismáticas capazes de encabeçar governos

\footnotetext{
${ }^{4}$ Sobre este assunto, cf. a discussão de Feres Jr. (2005) sobre a tipologia das formas de desrespeito e o lugar que o conceito de América Latina ocupa na linguagem cotidiana dos Estados Unidos, principalmente durante a presidência de John Fitzgerald Kennedy (1917-1963) entre 1961 e 1963. Já Hobsbawm (1997) aponta que a gestão de Kennedy, em uma escala global, mobilizou linguagens como "ocidente" e "cristianismo" para fazer frente à URSS "Comunista" e "ateia" com o intuito de manter a supremacia e a dominação estadunidenses no mundo.
} 
e de fazer frente aos interesses dos Estados Unidos na região transformaram o socialismo latino-americano em uma espécie de cartilha que deveria seguir as táticas usadas em Cuba.

Devido a isso e pelo fato de as esquerdas latino-americanas terem uma configuração parecida em toda a região, com os partidos comunistas marginalizados e intransigentes em suas doutrinas políticas, a guerrilha reabilitou a Revolução Socialista (aos moldes soviéticos) como única forma de triunfo histórico e evidenciou a necessidade de uma figura forte capaz de conduzi-la, principalmente quando era associada às experiências do passado ligadas à prática da rebeldia. Desse modo, em consonância com as diretrizes leninistas, era fundamental que os dirigentes dos partidos fossem intelectuais comprometidos não apenas com a construção da consciência coletiva, mas com a luta revolucionária.

O intelectual, nessa circunstância, se torna ao mesmo tempo "militar" e "evangelizador", isto é, integrante de uma vanguarda que reage contra a opressão (interna e externa) e procura apagar o passado em função do futuro. A ambiguidade, nesse caso, é que a luta revolucionária, surgida enquanto gesto antiautoritário, prepara terreno para o autoritarismo vanguardista que molda a sociedade segundo seus princípios e em função de seus interesses. Assim, intelectuais e dirigentes à frente desses partidos e movimentos revolucionários, para garantir seus interesses, não apenas excluem quaisquer possibilidades de acordos sociais, como "engolem" a própria sociedade onde foram gestados.

Contudo, entre 1968 e 1971, essa conduta revolucionária adotada pela esquerda alinhada com Cuba e a URSS, foi questionada tanto pelos grupos de esquerda avessos aos crimes cometidos por Josef Stalin (1879-1953), durante seu governo entre 1927 e 1953, quanto pela presença da nova esquerda na América Latina (KEUCHEYAN, 2013). Nesses anos, com discute Kagarlitsky (1988), a reforma política da URSS, iniciada por Nikita Khrushchov (1894-1971), foi freada pela burocracia e pela ascensão de Leonid Brejnev (1906-1982) que, ao assumir o governo em 1964, adotou práticas repressivas que culminariam, por exemplo, na invasão da Tchecoslováquia (1968) e na censura e na perseguição de intelectuais contrários ao seu governo. 
Nesse período da União Soviética, o tempo pareceu parar e as lutas política e de classe estagnaram porque o governo bloqueou as reações e as reformas ao construir um ideal de estabilidade vinculado à imobilidade e ao esvaziamento do pensamento crítico que se opunha a essa direção. Diferente dos anos 1960, quando o movimento literário e a crítica à burocracia estatal encontravam apoio oficial do Estado, os anos 1970 trouxeram novas formas culturais e políticas que, além de descentralizadas, eram fragmentadas e contraditória entre si. Por um lado, isso impôs um retrocesso político, mas por outro serviu para abrir novas experiências.

A América Latina também teve um processo semelhante ao da União Soviética. Enquanto a década de 1960 foi um período de expansão e consolidação da atividade intelectual, a década de 1970 foi um período de contenção e retração para esse grupo. De um lado, isso foi causado pelos golpes e pelas ditaduras militares, e, do outro, pelo endurecimento da política cultural cubana que, a partir de 1971, passou a cobrar mais comprometimento dos envolvidos com a Revolução. Desse modo, a ideia de que era possível modificar a sociedade através da cultura ganhou outro sentido e a literatura, usada anteriormente pela esquerda como ferramenta de formação, em vez de produzir consenso e de agregar opiniões, serviu como elemento de polarização nos debates intelectuais e políticos.

\section{Cuba e Ángel Rama: entre a disciplina e a autonomia}

Entre 1968 e 1971, a cultura tornou-se objeto de disputa entre revolucionários - ligados ao governo cubano - e intelectuais - principalmente os estrangeiros que, até então, colaboravam com o Estado cubano. Seu início, como veremos nesta seção, situa-se no Congresso de Cultura de Havana e adquire no Primeiro Congresso de Educação e Cultura uma postura mais acabada, em que se passou a condenar qualquer posição crítica e contrária à Revolução. Esse endurecimento, de um lado, foi endossado tanto pelos dirigentes revolucionários como pelas alas da esquerda "ortodoxa", e, do outro, foi criticado pelos intelectuais que, embora tivessem relações com Cuba, possuíam um grau de autonomia, isto é, não tinham ligação direta com partidos políticos e governos.

Segundo Miskulin (2008), o Congresso de Cultura de Havana demonstrou a adesão mundial pela Revolução Cubana porque, entre 4 e 12 de janeiro de 1968, 
reuniu mais de quinhentos intelectuais de setenta países. Esse entusiasmo, em parte, era impulsionado pela esperança de que a ilha oferecesse um novo modelo de transformação social, diferente dos que existiam até então na URSS e no leste europeu. Outro objetivo do Congresso era aumentar o engajamento político dos intelectuais e conceituar a cultura como arma anti-imperialista vinculada às lutas do Terceiro Mundo, como o apoio à luta armada. Não à toa, no discurso de encerramento, Fidel Castro salientou a importância da vanguarda intelectual para ajudar a compreender os problemas contemporâneos e para conduzir as revoluções.

Contudo, ainda em 1968, o interesse que Cuba despertava internacionalmente entre as esquerdas tomou outra direção. Como as inúmeras manifestações internacionais, sobretudo a Primavera de Praga, influenciaram alguns acontecimentos internos na itha, o governo cubano decidiu apoiar a invasão soviética à Tchecoslováquia. Essa decisão também modificou a política externa cubana que, ao aproximar-se da URSS, tornou-se mais moderada ao optar por não estimular a guerrilha. Dentro da ilha, essa aproximação fez com que a institucionalização da Revolução seguisse os moldes soviéticos, espalhando-se por todos os órgãos do governo. Visto de fora, esse ato foi considerado, por muitos, como uma afronta ao modelo alternativo que Cuba poderia ter sido e às liberdades de expressão e de criação que, nos primeiros dez anos da Revolução, foram basilares para a manutenção do processo revolucionário.

Porém, já entre 23 e 30 de abril de 1971, o "ano da produtividade" em Cuba, durante o Primeiro Congresso de Educação e Cultura (1971), decidiu-se que as atividades artísticas e literárias, em oposição às tendências burguesas e de elite, deveriam consolidar e desenvolver uma cultura para as massas. Assim, de acordo com as diretrizes elaboradas na declaração do congresso, a respeito da atividade cultural em Cuba ficou decidido que

O socialismo cria as condições objetivas e subjetivas que tornam factíveis a autêntica liberdade de criação e, por fim, resultam condenáveis e inadmissíveis aquelas tendências que baseiam-se em um critério de libertinagem com a finalidade de mascarar o veneno contrarrevolucionário de obras que conspiram contra a ideologia revolucionária do socialismo e do comunismo, em que está hoje 
irrevogavelmente comprometido nosso povo e em cujo espírito se educam as novas gerações. (DECLARACIÓN, 1971, p. 81)

Decidiu-se também que as instituições "superestruturais" (como universidades, meios de comunicação em massa, instituições artísticas e literárias etc.), com seus agentes e trabalhadores, deveriam estar alinhadas com as condições políticas e ideológicas revolucionárias, pois influenciavam diretamente a política cultural e a manutenção da Revolução Cubana. Além disso, os concursos literários - nacionais e internacionais - e a outorga de prêmios pelas instituições do governo cubano também teriam que se adequar às novas regras e condições que, agora, excluíam escritores e intelectuais estrangeiros - latino-americanos ou não - cujas obras conflitavam e criticavam a ideologia revolucionária. Ou seja,

Os meios culturais [em Cuba] não [poderiam] servir de marco para a proliferação de falsos intelectuais que pretendem converter o esnobismo, a extravagância, o homossexualismo e demais aberrações sociais em expressões da arte revolucionária, alheias às massas e ao espírito revolucionário. (DECLARACIÓN, 1971, p. 82) ${ }^{6}$

A cultura é politizada, pois, nessas circunstâncias, passa a atuar sobre a realidade que a originou e a servir como ferramenta nas lutas dos povos que foram vítimas do colonialismo e da exploração capitalista. Desse modo,

A cultura, [assim] como a educação, não é e não pode ser apolítica ou imparcial, pois é um fenômeno social e histórico condicionado pelas necessidades das classes sociais e suas lutas e interesses ao longo da história. O apoliticismo [,então,] nada mais é do que um ponto de vista vergonhoso e reacionário a respeito da concepção e da expressão cultural. (DECLARACIÓN, 1971, p. 82)

\footnotetext{
5 No original lê-se: "El socialismo crea las condiciones objetivas y subjetivas que hacen factible la auténtica libertad de creación y, por ende, resultan condenables e inadmisibles aquellas tendencias que se basan en un criterio de libertinaje con la finalidad de enmascarar el veneno contrarrevolucionario de obras que conspiran contra la ideología revolucionaria en que se fundamenta la construcción del socialismo y el comunismo, en que está hoy irrevocablemente comprometido nuestro pueblo y en cuyo espíritu se educan las nuevas generaciones". A Declaración del Primer Congreso Nacional de Educación y Cultura, publicado primeiro na revista Casa de las Américas (1971) e republicada em Cuadernos de Marcha (1971), Montevidéu. Para este artigo, dada a dificuldade de acessar as publicações de Casa, utilizei o texto de Cuadernos.

${ }^{6}$ No original lê-se: "Los medios culturales no pueden servir de marco a la proliferación de falsos intelectuales que pretenden convertir el esnobismo, la extravagancia, el homosexualismo y demás aberraciones sociales, en expresiones del arte revolucionario, alejados de las masas y del espíritu de nuestra Revolución".

No original lê-se: "La cultura, como la educación, no es ni puede ser apolítica ni imparcial, en tanto que es un fenómeno social e histórico condicionado por las necesidades de las clases sociales y sus luchas e intereses a lo largo de la historia. El apoliticismo no es más que un punto de vista vergonzante y reaccionario en la concepción y expresión culturales".
} 
Está em jogo uma concepção de cultura diferente daquela defendida pela burguesia, pois, a eliminação dos elementos dessa classe (como o individualismo) e de seu regime (como o capitalismo) estariam relacionados com a desaparição da própria cultura. Ou seja, trata-se de uma distinção entre dois conceitos: o de civilização e de cultura. ${ }^{8}$

Como, desde o final do século XIX, a palavra civilização atrelou-se ao imperialismo, foi necessário buscar outras formas para designar a vida social. É assim que a palavra cultura, associada ao romantismo e ao pré-marxismo, surge como uma crítica àquele modelo nascente de capitalismo industrial baseado no colonialismo. Enquanto a civilização (associada à experiência francesa), como mostrou Eagleton (2011), indicaria o caráter sociável, o espírito cordial e as maneiras agradáveis, a cultura (associada à experiência germânica) teria um sentido mais solene, espiritual e crítico.

Desse modo, à medida que a civilização expõe suas contradições, a cultura torna-se um elemento crítico que expõe suas falhas e fraturas, indicando uma possível mudança. Devido a isso, no caso cubano, influenciado pelo marxismo, a contradição entre civilização e cultura faz com que os revolucionários construam uma crítica - com dimensão social - que extrapola o sentido do cultivo individual (bildung) e que serve de antídoto à alienação, sendo capaz de produzir uma energia criativa que permite-lhes transfigurar a ordem social em que se situam. Ela, dessa forma, expõe a alienação da vida social pela vida material e procura, ao mitigar as contradições entre uma e outra, unir aquilo que está separado.

Sendo assim, no modelo de cultura proposto pelo governo cubano, para a classe operária e para o povo trabalhador, a cultura que surge com a luta revolucionária é uma forma de conquistar e desenvolver o que existe de mais valioso no acervo cultural humano (cf. nota 8 deste artigo) e que anteriormente

\footnotetext{
${ }^{8}$ A ambiguidade do conceito de cultura surge da metáfora da "domesticação" e do refinamento do homem por ele mesmo. Quando usado no coletivo, a cultura transforma-se em uma forma de controle que modera os instintos "naturais" do homem. Já no século XIX, assimilada pelo conceito de evolução, a cultura ganha uma dimensão histórica que dá a esse processo de cultivo um sentido aprimorado pela ideia de progresso. Por volta do século $X X$, esses sentidos ganham outras conotações quando se relacionam com outras palavras como, por exemplo, as "instituições culturais" que, além de preservar as fontes de refinamento do homem, permitem sua continuidade (WAGNER, 2010).
} 
Lhes era negado pela classe dominante e pela exploração. É sob essas circunstâncias que o intelectual revolucionário deve dirigir sua obra para erradicar os vestígios da velha sociedade que ainda subsistem na transição do capitalismo para o socialismo.

Nesse quadro, a plena formação do homem resulta do desenvolvimento de todas as capacidades que a sociedade pode promover nele. Ou seja, em uma sociedade comunista, da forma como conceituam, não existem travas para o desenvolvimento integral dessa cultura, desde que ela tenha um sentido coletivo. Por isso, é fundamental que a educação socialista - com as demais forças organizadas da sociedade - atinja todas as manifestações artísticas e literárias, a fim de produzir uma formação multilateral vinculada, também, à educação tecnocientífica, político-ideológica, moral e estética.

Como a base da cultura cubana era a mescla do africano escravizado com o espanhol, Cuba adquiriu características próprias e capacidade de assimilar elementos da cultura universal através das lutas de independência. Influenciado pela obra e pela ação de José Martí (1853-1895), o povo cubano desenvolveu uma corrente revolucionária que foi combatida por outra, entreguista e reacionária, que aliando-se ao imperialismo estadunidense rearticulou uma neocolonização e a “colonização do gosto estético” cubanas (DECLARACIÓN, 1971, p. 83). Portanto, tanto a revolução de 1959 como os intelectuais ligados a ela, ao romperem com o imperialismo, tornam-se herdeiros desse passado cultural que ganha novo sentido inserido nas novas circunstâncias históricas propiciadas.

A Revolução propiciou aos escritores e intelectuais cubanos condições mais favoráveis do que as anteriores. A fim de implementar um modelo alternativo ao capitalismo, o governo cubano nacionalizou o ensino e os meios de comunicação de massa, ofereceu bolsas e criou organismos culturais que contribuíram para que o povo cubano pudesse ter acesso às peças de teatro, aos livros, ao cinema e à arte. Contudo, isso só foi possível porque também, desde o início, a Revolução teve a solidariedade internacional de outros intelectuais.

Porém, segundo a declaração, entre os que a defenderam, havia outro grupo de "intelectuais pequeno-burgueses e pseudo-esquerdistas que utilizaram a Revolução como trampolim para ganhar prestígio ante os povos subdesenvolvidos" 
(DECLARACIÓN, 1971, p. 83). Ou seja, segundo essa perspectiva, eram oportunistas, que procuravam atuar como juízes da Revolução e portadores de uma nova colonização, baseada em valores políticos e culturais gestados nas capitais do mundo ocidental.

É nesse sentido que a cultura adquire um tom mais político do que formativo, ou seja, serve mais para construir e consolidar o socialismo, ao denunciar as mazelas do colonialismo, do que para construir uma alternativa real ao modelo existente. É como se o embargo, o imperialismo e a presença militar estadunidenses servissem para transformar a arte em uma arma da Revolução, esvaziada de reflexão e de debates, pois, para construir uma moral combativa, ela torna-se um instrumento contra a penetração do inimigo. Arte e literatura, então, servem para formar a juventude segundo os princípios revolucionários que, em contraste com a moral burguesa, interpretam a cultura em uma sociedade coletivista como atividade das massas que não é monopólio da elite e nem de pequenos grupos que a usam como adorno.

Assim, fora do quadro propiciado pela Revolução, nem os escritores latinoamericanos, que em suas obras retratavam o drama do continente, escapavam das críticas, pois quem emigrasse para a Europa ou para os Estados Unidos independente das razões - era considerado falso, por romper com suas origens e por se tornar agente do colonialismo cultural. O intelectual - que anteriormente gozava de privilégio e status, agora, deveria abrir mão da "arrogância senhorial", apontada por Vladimir Lenin (1870-1924), e não atribuir a si o papel de crítico caso houvesse abandonado a luta revolucionária - vinculado ao mundo dos "salões burgueses e editoriais do imperialismo" estaria impossibilitado não apenas de retratar os povos e as realidades da América Latina como também de julgar suas revoluções e lutas de liberação nacional (DECLARACIÓN, 1971, p. 84).9

Como mostrou Gilman (2012), em pouco menos de doze anos, entre 1959 e 1971, a política cultural cubana desenvolveu um sentimento de anti-intelectualismo e subordinou-se às premissas revolucionárias. Dentro de Cuba, o político moldou

\footnotetext{
9 O raciocínio deste e dos últimos parágrafos orienta-se no texto da Declaración del Primer Congreso Nacional de Educación y Cultura, publicado pela primeira vez na revista Casa de las Américas (1971) e republicado em Cuadernos de Marcha (1971), Montevidéu.
} 
diretamente a criação artística e literária, pois os intelectuais, além de prescindir do apoio estatal, não possuíam lugares de mediação próprios ou que controlassem inteiramente. Fora da ilha, a polarização entre culturas burguesa e revolucionária alastrou-se velozmente e produziu um conjunto de ambiguidades, principalmente por causa do conceito marxista de vanguarda que, de um lado, fundamentava uma teoria para emancipar o presente e, por outro, considerava toda reflexão teórica como burguesa e universitária.

Embora entre as décadas de 1950 e 1960, os intelectuais fossem atraídos pelo Estado com intenção de projetar e trabalhar na execução de políticas públicas, a partir dos anos 1970 essa relação foi sendo cada vez mais esvaziada a ponto de se tornar contraditória. Esse esvaziamento, de um lado, foi causado pelo antiintelectualismo sustentado, ambiguamente, por intelectuais que subordinavam a reflexão, a crítica e a criação cultural e científica à ideologia e à política (tanto à esquerda como à direita). Sob esse entendimento, atividades como literatura e cultura possuíam funções puramente pedagógicas. Ou seja, não eram consideradas estruturas independentes e de significado, com capacidade de incidir sobre a realidade histórica e social, de portar uma verdade conceitual, um conjunto de valores políticos e de possuir formas próprias, pois ambas eram construídas e interpretadas segundo critérios ideológicos prévios e que regulavam sua produção.

Do outro lado, esse anti-intelectualismo, em vez de evidenciar falhas no acesso à cultura e a distância da cultura letrada em relação à população, tratou a reflexão intelectual e a criação teórica como elementos subversivos, pois poderiam produzir descontinuidades nos elementos que naturalizavam e ordenavam o discurso propalado pelo poder. Assim, nos regimes políticos tanto à direita quanto à esquerda, em detrimento de uma cultura cosmopolita e continental, gestada anteriormente, reavivou-se a estética romântica do século XIX e o apelo às ideias de autenticidade e de valorização da cultura nacional. Não à toa, o fazer literário e a criação estética tornaram-se antíteses do conceito de político e das decisões políticas $^{10}$ quando não construídos segundo princípios externos previamente estabelecidos (AVELAR, 2003).

\footnotetext{
${ }^{0}$ É interessante retomar a distinção elaborada por Schmitt (1992) entre o político e política para compreender que palavras e conceitos políticos (como democracia, revolução e liberdade) não portam significados e ideias, pois seus significados surgem dos problemas que indicam.
} 
Como argumenta Funes (2014), o anti-intelectualismo foi mais forte nas ditaduras do Cone Sul, onde através da intervenção política esses governos procuraram modificar o Estado, a sociedade, a economia, a cultura e, inclusive, a subjetividade individual. Através de preceitos estabelecidos pela Doutrina de Segurança Nacional (cf. nota 2 deste artigo), esses governos construíram aparatos de repressão para combater o inimigo interno que, de fato, serviam para disciplinar movimentos sociais, adequar economias nacionais aos interesses dos capitais internacionais e sujeitar a população através da força a fim de impossibilitar quaisquer críticas e demandas por direitos.

Contudo, em relação à Revolução Cubana, segundo o apontamento de Rojas (2018), a questão da adesão ou do rechaço a Cuba ficou mais evidente na primeira metade dos anos 1970 com o governo revolucionário construindo um Estado vinculado ao socialismo real adotado pelo governo de Brejnev na URSS. IsSo não apenas ressignificou a relação dos intelectuais com a burocracia estatal, como serviu de marco para a construção de uma crítica e de um pensamento latinoamericanos, pois, até então, Cuba era o único Estado do continente plenamente envolvido na construção de modelos teóricos e hegemônicos para a cultura e a literatura. ${ }^{11}$

Sendo assim, no discurso de encerramento do Congresso, proferido em 1 o de maio de 1971, não espanta que Fidel Castro tenha montado um conjunto de polarizações (como dentro/fora de Cuba, imperialismo/colonialismo, liberalismo/marxismo) para articular a existência de uma guerra ideológica e cultural com o objetivo de acabar com a Revolução. O problema, na verdade, é que os agentes dessa guerra tenham sido os intelectuais que anteriormente ajudaram Cuba ao divulgar as mudanças e os impulsos da Revolução, mas que por causa de suas escolhas tornaram-se burgueses e agentes da CIA. Devido a isso, eles depararam-se com um país que, se antes prescindiu da ajuda deles, agora, estava fechado "por tempo indefinido e tempo infinito".

\footnotetext{
${ }^{11}$ O que está em jogo, neste caso, é a disputa em torno do boom literário pois, se de um lado existe uma estética que, embora extremamente politizada, escapa às discussões do governo cubano, do outro há uma estética alinhada aos interesses revolucionários. Cf. também a discussão de COSTA (2013) sobre este assunto.
} 
A palavra intelectual, nesse caso, assume significados diferentes segundo o contexto em que é usada, podendo ter uma conotação positiva ou negativa. Assim, no caso cubano, se fosse alinhado ao regime e à Revolução, era alguém comprometido e que possivelmente integraria a vanguarda responsável por transformar a sociedade, mas, se fosse crítico ou houvesse rompido com o regime, era considerado falso e burguês, pois trabalhava para enfraquecer o socialismo em Cuba. Esse discurso evidencia não apenas a perda de prestígio, mas uma mudança no significado e na função que o intelectual ocupava dentro daquela sociedade e naquele contexto.

O intelectual dos anos 1970, especialmente na América Latina e no Terceiro Mundo, deixa de ser alçado à condição de agente de transformação social'12, cuja missão é alterar o curso da história ao contribuir para o engrandecimento espiritual e para a estruturação de uma nova sociedade. A Revolução Cubana, então, acompanhando as tendências da época, catalisou esses aspectos, mas, já no final da década, esse impulso foi freado pela opção de centralizar a produção artística e cultural e boicotar quem criticasse o regime. Desse modo, enquanto no primeiro momento os principais escritores vinculados ao chamado boom literário do romance latino-americano se identificaram com a Revolução Cubana, no segundo, procuram afastar-se.

Um exemplo disso encontra-se na instituição Casa de las Américas que, através de sua revista e dos concursos, cumpriu um papel fundamental para articular e aprimorar as constelações intelectuais nesse período, ajudando, inclusive, a aproximar partes distantes da América Latina, além de permitir a esses escritores um contato com a esquerda europeia - especialmente a da Espanha,

\footnotetext{
12 Influenciados pelas ideias e leituras de Sartre (sobre literatura e engajamento), Wright Mills (sobre o intelectual enquanto ator social fundamental e único capaz de transformar a sociedade), Antonio Gramsci (sobre sujeito e iniciativa revolucionários e pelo modo como pensava a relação entre intelectuais e massas), Max Horkheimer, Theodor Adorno e Hebert Marcuse - membros da Escola de Frankfurt - (sobre a suavização das contradições do século XIX entre proletariado e capital, indivíduo e sociedade, alta cultura e baixa cultura) e, também, por Ernesto "Che" Guevara (sobre as vanguardas políticas e a revolução), os intelectuais latino-americanos deste período ganharam protagonismo, mas também viram suas funções sendo conformadas diretamente pela lógica do mercado que definiu tanto o valor da cultura como o de seus pensamentos. Em Cuba, particularmente, Guevara (1965) instilou a ideia de um "pecado original" entre intelectuais e artistas dos anos 1950 que, a seu ver, não eram "autenticamente revolucionários” porque não estavam comprometidos com a causa da Revolução. Ideias como essa de "Che” contribuíram, e muito, para espalhar entre as esquerdas latino-americanas o sentimento de "anti-intelectualismo".
} 
onde estavam as principais editoras do boom. Entre 1968 e 1971, devido às inúmeras mudanças políticas que afetaram a cultura e ao aumento nos casos de estigmatização pública de escritores cubanos (José Lezama Lima [1910-1976], Heberto Padilla [1932-2000], Reinaldo Arenas [1943-1990], etc.), que na década de 1970 foram marginalizados ou exilados, grande parte dos intelectuais de esquerda da América Latina, e do Ocidente ${ }^{13}$, afastam-se do socialismo cubano.

Contudo, foram as prisões do poeta Heberto Padilla e de sua esposa, a poetisa Belkis Cuza Malé (1942), em 1971, e a autocrítica de Padilla que produziram uma mudança sem volta na relação dos intelectuais latino-americanos com Cuba, principalmente entre os da esquerda. A adoção de premissas soviéticas, como o "realismo socialista" e o "materialismo dialético e histórico", que sustentava o "comunismo científico", não apenas provocou uma metamorfose cultural, mas também fraturou o campo intelectual cubano ao acelerar, entre 1970 e 1980, o êxodo de artistas, escritores e acadêmicos.

Passado esses acontecimentos, Roberto Fernández Retamar (1930-2019), que na época era diretor da revista Casa de las Américas, no ensaio intitulado "Caliban"14, sistematizou as novas posições culturais assumidas por Cuba e adotou o tom de polêmica e acusação em relação aos intelectuais burgueses europeus (ou que pretendiam ser), nostálgicos do colonialismo, e que supostamente não aceitavam a liberdade e a autonomia da América Latina, além de criticar os intelectuais latino-americanos contrários à Revolução Cubana e que vinculavamse às instituições "imperialistas". ${ }^{15}$ Desse modo, apelava para que escritores e artistas do continente combatessem, veladamente ou não, o colonialismo cultural e político que reiterava essa condição e que excluía Cuba do chamado "mundo livre".

\footnotetext{
${ }^{13}$ Rojas (2016) mostra que, durante a década de 1970, a cidade de Nova Iorque, enquanto centro de diferentes movimentos progressistas, abrigou uma ala da nova esquerda que recebeu e interpretou de modo crítico os rumos da revolução cubana, sobretudo, pelo alinhamento com Moscou.

${ }^{14}$ Esse ensaio saiu pela primeira vez no número 68 da revista Casa de las Américas, publicado em setembro e outubro de 1971, logo após o Primeiro Congresso Nacional de Educação e Cultura.

15 Nomes como os de Jorge Luis Borges (1899-1986), Emir Rodríguez Monegal (1921-1985), Severo Sarduy (1927-1993), Carlos Fuentes (1928-2012) e Guillermo Cabrero Infante (1929-2005) são mencionados por Fernández Retamar como exemplos de latino-americanos que têm predileções pelos Estados Unidos e pela Europa, principalmente os quatro últimos que trabalharam e publicaram para a revista Mundo Nuevo (1966-1971), publicação financiada pela CIA que contribuiu para divulgar e conformar o chamado boom literário latino-americano.
} 
Fernández Retamar, em sua posição de intelectual oficial, com intuito de construir um cânone literário e cultural vinculado aos interesses revolucionários de Cuba, também questionava as interpretações sobre a narrativa latino-americana elaboradas por outros críticos como, por exemplo, Ángel Rama. Nesse caso, embora ambos compartilhassem de uma mesma concepção revolucionária da literatura, o que diferenciava um do outro era que Fernández Retamar trabalhava oficialmente para o governo cubano, enquanto Rama poderia assumir uma posição mais independente e menos oficial, pois não estava vinculado diretamente a nenhum projeto político.

Desse modo, ao comentar a nova política cultural em Cuba, Rama (1971), que na década de 1960 usou as páginas de Marcha para divulgar a cultura da Revolução Cubana e que também serviu como jurado em várias edições do prêmio Casa de las Américas, acusou o governo cubano de produzir querelas intelectuais esquemáticas e manifestações exibicionistas, como a autocrítica de Padilla, que prejudicavam e afetavam a vida cultural e artística do país. Diante disso, o primeiro erro em relação a essa política foi sua adoção em um clima emocional carregado no qual as resoluções do Primeiro Congresso de Educação e Cultura, gestadas anteriormente, foram afetas pelo discurso de encerramento de Fidel Castro.

Diferenciar socialismo e sua construção, em um determinado país, das outras lutas populares nas sociedades burguesas também seria um erro. Como cada revolução socialista no século XX, segundo Rama, tinha suas peculiaridades, o problema seria a insistência em transpor o modelo soviético, praticado na década de 1930, para sociedades, culturas e experiências históricas muito diferentes, inclusive, quando, já dentro da URSS, esse modelo dava sinais de crise e se dissolvia em formas não previsíveis. O problema cubano foi vincular sua luta por transformação a conflitos de outros lugares, nos quais eles não podiam agir diretamente. Com isso, a preocupação de Rama era que as letras latino-americanas seguissem o modelo cubado ao desconsiderar suas especificidades de produção e criação.

Ainda segundo Rama, no contexto da nova política cultural cubana, outro erro seria teorizar a destruição do antigo regime e a construção da nova sociedade sem que houvesse uma expressão teórica das mudanças. Um exemplo disso é que, 
desde 1961, a intelectualidade cubana pautava suas criações segundo o discurso "Palabras a los intelectuales" de Fidel Castro, um texto que, embora fosse de transição, regulou, por mais de uma década, o funcionamento da vida cultural, a organização e o desenvolvimento das principais instituições culturais cubanas. Esse discurso, que serviu como uma cartilha, não foi discutido até meados de 1968, ano que culminou com diferentes teorias artísticas reinterpretando-o e manifestandose sem anuência do governo. Contudo, segundo Rama, como essas diferentes posições atravessaram toda a Revolução sem serem acomodadas e reguladas por uma discussão estética, a nova política cultural produziu um choque no momento em que o governo cubano percebeu seu atraso em relação à cultura gestada e desenvolvida pela sociedade e seus agentes.

Por fim, mas não menos importante, existiam os problemas do subdesenvolvimento econômico e da desinformação sobre questões contemporâneas tanto em Cuba como na América Latina. O embargo imposto pelos Estados Unidos e a falta de diálogo entre países latino-americanos produziam uma espécie de diálogo surdo, com os intelectuais falando para o vazio. Isso, todavia, não poderia servir de material para que as instituições culturais cubanas como Casa de las Américas - acusassem os intelectuais e críticos, latinoamericanos ou não, e que concordassem ou não com os rumos da Revolução Cubana, de conspirarem a favor do imperialismo. Também seria um erro afirmar que toda crítica pública e discordância em relação a Cuba servisse à direita e ao imperialismo, pois, como escreveu Rama (1971), a ambiguidade dessa atitude é que, além das acusações sem provas, transformarem todos os críticos e intelectuais em agentes da CIA, sem perceber que alguns deles simplesmente, não sendo membros da CIA, faziam "livremente" o que ela desejava, isto é, apontavam erros e excessos da Revolução Cubana.

Isso não corresponderia aos acontecimentos, porque, de acordo com a interpretação de Rama, um dos setores que mais contribuiu para apoiar e difundir a Revolução Cubana, explicando-a para outros grupos sociais, foram os intelectuais e artistas que, inicialmente, procediam de diferentes correntes filosóficas e políticas como o liberalismo, o comunismo, o existencialismo e o cristianismo, aglutinados, sobretudo, para combater e condenar o imperialismo. Não à toa, ainda 
em 1968, Fidel Castro, no discurso de encerramento do Congresso Cultural de Havana, elogiava os intelectuais que agiam livremente e fora das estruturas partidárias e das igrejas, compondo uma "legítima vanguarda universal".

Assim, no início, havia uma liberdade total das formas literárias e artísticas, mas com restrição dos conteúdos (que deveriam estar adequados aos critérios revolucionários). De acordo com Rama, estava mais ou menos claro qual era e onde situava-se o limite, que parecia fácil de sentir, porém, era difícil de ser codificado pelos regulamentos burocráticos. Essa abertura, entretanto, nada tinha a ver com as soluções estéticas adotadas pelos soviéticos na década de 1930, sobretudo, porque a crítica elaborada por Ernesto "Che” Guevara16 (1928-1967), contra o "escolasticismo marxista", tinha a intenção de investigar e desenvolver novas teorias políticas, econômicas e culturais (RAMA, 1971).

Contudo, como apontou Rama, embora o Congresso Cultural de Havana não houvesse formulado uma doutrina estética, a partir desse momento despontaram questões como a coincidência entre vanguarda artística e vanguarda política e como a desagregação entre a decadência da sociedade capitalista e suas formas criativas que, posteriormente, serviram de base para a nova política cultural cubana que passou a manejar conceitos como o de "arte revolucionária" e de "decadência". Assim, o entendimento de que toda arte genuína serviria revolucionariamente à humanidade, sem que tivesse preocupações políticas, modificou-se para o de que a arte deveria politizar-se para cumprir funções concretas (RAMA, 1971, p. 53).

Além do mais, após a invasão à Tchecoslováquia que pôs fim a "Primavera de Praga”, os intelectuais que apoiavam a Revolução Cubana afastaram-se devido ao apoio que Fidel Castro deu a URSS. Esse apoio não apenas produziu uma cisão entre os intelectuais e o governo cubano que, até aquele momento, trabalhavam conjuntamente como, também, gerou um desencontro entre os interesses nacionais cubanos e as ideologias - ligadas a uma esquerda independente - que circulavam pela América Latina e pela Europa acusando o governo soviético de interferir tanto na liberdade de expressão como na soberania nacional.

\footnotetext{
${ }^{16}$ Os detalhes dessa teoria estão no texto "O socialismo e o homem em Cuba", que Guevara enviou para Carlos Quijano em 1965. Cf. nota 12 deste artigo em que se menciona a ideia de "pecado original” dos intelectuais e artistas, que não eram “autenticamente revolucionários”.
} 


\section{Conclusão}

Contrário a essa postura do governo cubano, Rama não fica apenas na crítica, mas também procura oferecer alternativas ao caminho escolhido. Mencionando o nome de Teodoro Petkoff'17 (1932-2018), que era um dos dirigentes do partido comunista venezuelano e que, em seguida, fundou o Movimento al socialismo, ele fala de um político e intelectual que em vez de aceitar as diretrizes da URSS encarou o problema dos intelectuais dentro do socialismo. Segundo Rama, Petkoff, ao analisar a Primavera de Praga, procurou resgatar o conceito de intelectual enquanto "consciência crítica" da sociedade, sobretudo, porque ele buscava desenvolver um movimento de massas capaz de transformar as fundações de um Estado burguês dinâmico e rico, inserido no capitalismo, enquanto Castro, já dentro de um Estado socialista, optou por aprofundar o socialismo ao ponto de "guinchar" a estrutura cultural do país segundo as necessidades políticas (RAMA, 1971, p. 56). Ou seja, enquanto Petkoff fez contraponto ao modelo soviético, Fidel o acentuou.

Outro ponto, talvez o mais importante, é que a partir do momento em que a Revolução optou por abandonar as formas ecléticas a fim de estruturar uma coesão do corpo social, a ponto de sacrificar a cultura, a ruptura com os intelectuais progressistas e burgueses era inevitável, pois para erradicar os vestígios da cultura anterior era fundamental que os intelectuais estivessem vinculados ao socialismo. Desse modo, em Cuba, há outras questões que definem a adoção de uma nova política cultural e submetem as letras segundo os postulados da Revolução.

Como Rama enumera, a difícil situação da economia, desarticulada pelo embargo, a planificação dos recursos, o aproveitamento mais rígido das forças de trabalho, a eliminação das estruturas individualistas, entre outras medidas, forçou uma modificação brusca da sociedade e de sua cultura. Ademais, como a revolução propiciou que as classes de camponeses urbanizados e de alfabetizados pudessem ocupar cargos de pequeno e médio escalão, além de participar nos elementos de estrutura social, essa estrutura ficou mais evidente nas forças armadas que, através da disciplina, deslocou as organizações partidárias existentes e thes deu um papel fundamental na reorganização da ideologia e das normas culturais.

\footnotetext{
17 Em Checoslovaquia: el socialismo como problema (1966), Petkoff faz um exame amplo e
} detalhado do intelectual dentro do socialismo. 
Então, se no Congresso Cultural de Havana, em 1968, haviam se definido valores anti-imperialistas e anticapitalistas que reivindicavam o espírito crítico da vanguarda artística e dos intelectuais, além da construção de um socialismo mais aberto, já em 1971, depois do Primeiro Congresso de Educação e Cultura, Cuba avança em outra direção. Ou seja, a abertura proposta anteriormente, em vez de se concretizar, transforma-se em uma espécie de comprometimento político que deve ser seguido à risca. Não à toa, para concluir, Rama menciona a dificuldade dos intelectuais em criar modelos alternativos de sociedade e cultura, pois a crítica e o pensamento não propõem efetivamente nada de concreto se não estiverem de acordo com os princípios políticos.

\section{Referências}

ADELMAN, Jeremy. Unfinished States: historical perspectives on the Andes. In: DRAKE, Paul W.; HERSHBERG, Eric (eds.). State and society in conflict. comparative perspectives on Andean crises. Pittsburgh: University of Pittsburgh Press, 2006.

ALTARMIRANO, Carlos (org.). Élites culturales en el siglo XX latinoamericnao. Historia de los intelectuales en América Latina: II. Los avatares de la "ciudad Letrada" en el siglo XX. Buenos Aires; Madrid: Katz, 2010.

AVELAR, Idelber. Alegorias da derrota: a ficção pós-ditatorial e o trabalho de luto na América Latina. Tradução de Saulo Gouveia. Belo Horizonte: Ed. UFMG, 2003.

COSTA, Adriana Vidal. Intelectuais, política e literatura na América Latina: o debate sobre revolução e socialismo em Cortázar, García Márquez e Vargas Llosa. São Paulo: Alameda, 2013.

DECLARACIÓN del Primer Congreso Nacional de Educación y Cultura. Cuadernos de Marcha, Montevideo, n. 49, p. 69-85, mayo 1971.

FERES JR. João. História do conceito de "Latin America" nos Estados Unidos. Bauru: EDUSC, 2005.

FRANCO, Jean. The decline and fall of lettered city. Latin America in the Cold War. Cambridge, Massachusetts: Harvard University Press, 2002.

FUNES, Patricia. Historia mínima de las ideas políticas en América Latina. México, D.F.: El Colegio de México, 2014. 
GILMAN, Claudia. Entre la pluma y el fusil: debates y dilemas del escritor revolucionario en América Latina. 2. ed. ampl. Buenos Aires: Siglo Veintiuno, 2012.

GONZÁLEZ ALEMÁN, Marianne; PALIERAKI, Eugenia (comps.). Revoluciones imaginadas: itinerarios de la idea revolucionaria en América Latina contemporánea. Santiago: RIL editores, 2012.

GUEVARA, Ernesto. El socialismo y el hombre en Cuba. Marcha, Montevideo, año XXVI, n. 1246, p. 14-15, 12 mar. 1965.

HOBSBAWM, Eric. Era dos extremos: o breve século XX: 1914-1991. 2. ed. Tradução de Marcos Santarrita. São Paulo: Cia. das Letras, 1997.

IBER, Patrick. Niether peace nor freedom: the cultural Cold War in Latin America. Cambridge, Massachusetts: Harvard University Press, 2015.

KAGARLITSKY, Boris. The thinking reed: intellectuals and the Soviet State from 1917 to the present. London: Verso, 1988.

KEUCHEYAN, Razmig. Hemisferio izquierdo: un mapa de los nuevos pensamientos criticos. Madrid: Siglo XXI, 2013.

KOSELLECK, Reinhart. Critérios históricos do conceito moderno de revolução. In: FUTURO PASSADO: contribuição à semântica dos tempos históricos. Rio de Janeiro: Contraponto, 2011.

MISKULIN, Sílvia Cezar. O ano de 1968 em Cuba: mudanças na política internacional e na política cultural. Esboços: história em contextos globais, Florianópolis, v. 15. n. 20, p. 47-66, 2008. Disponível em: https://periodicos.ufsc.br/index.php/esbocos/article/viewFile/10242/9541. Acesso em: 6 abr. 2020.

PADRÓS, Enrique Serra. A ditadura cívico-militar no Uruguai (1973-1984): terror de Estado e Segurança Nacional. In: WASSERMAN, Claudia; GUAZZELLI, Cesar Augusto Barcellos. Ditaduras militares na América Latina. Porto Alegre: Ed. UFRGS, 2004.

PIPETONE, Ugo. La esperanza y el delirio: una historia de la izquierda en América Latina. Ciudad de México, D.F.: Taurus/CIDE, 2015.

RAMA, Ángel. El boom en perspectiva. La crítica de la cultura en América Latina. Caracas: Biblioteca Ayacucho, 1985.

RAMA, Ángel. Una nueva política cultural en Cuba. Cuadernos de Marcha, Montevideo, n. 49, p. 47-68, mayo 1971. 
ROJAS, Rafael. Traductores de la utopía: la revolución cubana y la nueva izquierda de Nueva York. Ciudad de México, D.F.: [s.n.] 2016.

ROJAS, Ricardo. La polis literaria: el boom, la revolución y otras polémicas de la Guerra Fria. Ciudad de México, D.F.: Taurus/CIDE, 2018.

ROUQUIÉ, Alain. Os militares na política latino-americana após 1930. In: BETHELL, Leslie. A América Latina após 1930: estado e politica. São Paulo: EDUSP, 2009. v. 8.

SCHMITT, Carl. O conceito do político. Petropolis: Vozes 1992.

EAGLETON, Terry. A ideia de cultura. 2. ed. São Paulo: Ed. UNESP, 2011.

WAGNER, Roy. A invenção da cultura. São Paulo: Cosac Naify, 2010. 